\title{
Sero-prevalence of hepatitis B virus and associated factors among pregnant women in Gambella hospital, South Western Ethiopia: facility based cross-sectional study
}

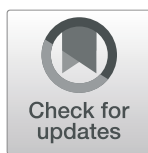

\author{
Abayneh Tunje Tanga ${ }^{3^{*}}$ D, Misanew Andargie Teshome ${ }^{1}$, Desta Hiko ${ }^{2}$, Chaltu Fikru ${ }^{2}$ and Gemechu Kejela Jilo ${ }^{3}$
}

\begin{abstract}
Background: Hepatitis B virus (HBV) is a hepatotropic deoxyribonucleic acid (DNA) virus which causes death. More than 300 million people have chronic liver infections globally and about 600,000 people die annually from acute or chronic complications of hepatitis B infection. Recent studies conducted in Ethiopia showed moderate endemicity (3-7.8\%) of HBV among pregnant women. However, there is paucity of information on sero- prevalence of HBV and associated factors among pregnant women at Gambella town. The aim of this study is to assess sero-prevalence of hepatitis surface antigen ( $\mathrm{HBsAg}$ ) and associated factors among pregnant women in Gambella Hospital.

Methods: Hospital based cross-sectional study was conducted in a total of 253 pregnant women from March 10April 15, 2017. Socio-demographic characteristics and risk factors were collected through face to face interview using structured questionnaire. HBV infection was determined using Eugene strip test. Logistic regression analysis was used to determine association between $\mathrm{HBsAg}$ sero-positivity and various factors. Findings were presented using 95\% Cl of Crude Odds Ratios (COR) and Adjusted Odds Ratios (AOR).

Result: The overall sero- prevalence of HBV infection was 7.9\% (95\% Cl, 4.7-11.9), which indicates intermediate endemicity. History of abortion ( $A O R=3.56: 1: 95 \% \mathrm{Cl}, 1.24-10.22$ ), occupation ( $\mathrm{AOR}=8.36: 95 \% \mathrm{Cl}, 1.67-41.96)$ and multiple sexual partner ( $\mathrm{AOR}=17.38: 95 \% \mathrm{Cl}$, 4.48-67.49) had statistical significant association with HBsAg sero-positivity.

Conclusion: HBV sero-prevalence in pregnant women shows intermediate endemicity. Hence health education on having single sexual partner and risk factors of abortion should be given. In addition, routine screening and immunization of pregnant women for HBV infection should be strengthen.
\end{abstract}

Keywords: Hepatitis B virus, Sero-prevalence, Eugene test strip, Risk factors, Pregnant women, Gambella

\section{Background}

Hepatitis B virus is a hepatotropic deoxyribonucleic acid (DNA) virus which occurs through immune-mediated killing of infected liver cells. It is also recognized as oncogenic virus that can cause a higher risk of developing hepatocellular carcinoma [1]. It is 50-100 times more infectious than HIV [2]. The infection with the hepatitis B virus can be lifelong, causing cirrhosis (liver

\footnotetext{
* Correspondence: abaynehtun@gmail.com

${ }^{3}$ Arba Minch University College of health science, Arba Minch, Ethiopia

Full list of author information is available at the end of the article
}

scarring), liver cancer, liver failure, and death. It can be acute (with discrete onset of symptoms and jaundice or elevated serum ALT > $100 \mathrm{IU} / \mathrm{L}$ or chronic with no symptoms. The rate for chronicity is approximately $5 \%$ in adult infections, but it reaches $90 \%$ in neonatal infections $[3,4]$.

More than 300 million people have chronic liver infections globally and about 600,000 people die annually from acute or chronic complications of hepatitis B infection. Hepatitis B prevalence is highest in sub-Saharan Africa and East Asia, where between 5 and $10 \%$ of the adult population is chronically infected $[5,6]$.

(c) The Author(s). 2019 Open Access This article is distributed under the terms of the Creative Commons Attribution 4.0 International License (http://creativecommons.org/licenses/by/4.0/), which permits unrestricted use, distribution, and 
HBV places a heavy burden on the health care system because of the costs of treatment of liver failure and chronic liver disease (easily reaching up to hundreds of thousands of dollars per person). Chronic viral hepatitis also results in loss of productivity [5].

In countries where $\mathrm{HBV}$ is highly endemic (HBsAg prevalence rate of $8 \%$ or higher), most infections occur during infancy and early childhood [7]. Recent studies conducted in Ethiopia showed moderate endemicity (3-7.8\%) of HBV among pregnant women $[8,9]$.

Previous studies conducted in different parts of Ethiopia showed that history of use of sharp materials, having multiple sexual partners, ear pricing, abortion, Place of delivery, Genital mutilation, history of tooth extraction cesarean section and tattoo for cosmetics were associated factors for HBs Ag sero-positivity [8, 10-13].

HBV infection during pregnancy is closely related to high risks of maternal complications including: preeclampsia, placenta praevia, preterm delivery, placental separation, ante partum haemorrhage, preterm labour, increased incidence of intraventricular haemorrhage, gestational diabetes mellitus and mortality with a high rate of vertical transmission leading to fetal and neonatal hepatitis [14]. Transmission from mother to infant takes place in uterine, during delivery, and after birth. Children born to $\mathrm{HBsAg}+$ and hepatitis e antigen ( $\mathrm{HBeAg}+)$ mothers have $70-90 \%$ chance of prenatal acquisition of HBV infection and over $85-90 \%$ of them will eventually become chronic carriers of the disease. Chronic carriers of HBV are main reservoirs for continued transmission of $\mathrm{HBV}$ and have a higher risk of hepatocellular carcinoma and liver cirrhosis $[1,15,16]$.

Since HBV infected pregnant women are at risk of infecting their babies, knowing magnitude of HBV status and its risk factors in the area is very important. However, there is paucity of information on sero- prevalence of $\mathrm{HBV}$ and associated factors among pregnant women at Gambella town. Therefore, the aim of this study is to give deep insight on the magnitude of $\mathrm{HBV}$ and its associated factors among pregnant women in anti natal care (ANC) clinic of Gambella hospital.

\section{Methods}

\section{Study area and period}

Hospital based cross sectional study was conducted from March 10-April 15, 2017 in Gambella hospital. Gambella town is the capital of the Gambella regional state located at a distance of $768 \mathrm{k}$ meter in the south west away from Addis Ababa. Gambella Town has a total population of 74.102 of whom $47.2 \%$ are women. The town has one hospital, one health center, two governmental junior clinics and 15 private clinics. More than 20 pregnant women visit the hospital ANC clinic per day and get free ANC services.

\section{Population}

The source populations were all pregnant women who visited antenatal care unit at Gambella Hospital during the study period and fulfill selection criteria. All pregnant women whose pregnancy was confirmed by pregnancy test kit are the inclusion criteria and pregnant women who were critically sick and unable to answer questions were excluded from the study.

\section{Sample size and sampling}

The sample size was determined using single population proportion formula with the assumption of $95 \%$ confidence interval $(\mathrm{CI})$, Hepatitis $\mathrm{B}$ virus prevalence rate $6 \%$ [17], degree of precision of $3 \%$ and none-response rate of $5 \%$. Finally, the calculated sample size was 253 . The study participants were recruited using non-duplicative consecutive sampling method.

\section{Data collection}

Socio-demographic characteristics and associated risk factors for $\mathrm{HBV}$ and $\mathrm{HCV}$ infections were collected using structured questionnaire by trained health professionals. The study variables included in this study were maternal age, educational status, occupational status, place of previous birth, residence, abortion, hospital admission, surgical procedure history of blood transfusion, sharp injury, accidental needle stick injuries, splash of body fluids, genital mutilation, human bites, body tattooing, injection-drug use, history of multiple sexual practice and sharing earrings, razors, tooth brushes.

\section{Detection of HBsAg}

Five milliliters of venous blood was collected from each study participant by trained laboratory technologist. Serum was separated by centrifugation at $3000 \mathrm{rpm}$ for $10 \mathrm{~min}$. Each serum was subjected to HBsAg antibody rapid test (Shanghai Eugene Biotech co., Ltd) from Minhang, Shanghai, China, following the manufacturer's instruction. Eugene rapid test is a qualitative, solid phase, two-site sandwich immunoassay for the detection of HBs Ag in serum HBV infection status - was defined by a positive or negative result for $\mathrm{HBsAg}$ using HBsAg test strip.

\section{Data quality assurance}

To ensure quality of data, questionnaire was prepared in English language, translated to Amharic and re translated back to English by other person who can speak both languages. To make sure that the questionnaire is appropriate and understandable; it was pre-tested on $5 \%$ of pregnant women at Jimma hospital. Training was given for supervisors and data collectors for 1 day. The data collection process was supervised and the collected data were reviewed and checked for completeness by the 
principal investigator. Then collected data were checked for consistency and accuracy. Standard operating procedures were strictly followed during blood sample collection, storage and analytical process. Storage conditions and expired date of reagents were checked. Positive and negative control sera were run following the manufacturer recommendation of the kit. Finally, reliability was checked by using cronbach alpha (.701).

\section{Data analysis}

Collected data were checked for completeness and consistency, and coded manually. Then data were entered into Ep-idata version 3.1 and cleaned data were exported to SPSS version 21 windows to recode, compute and do other statistical analysis. In the univariate analysis a descriptive statistics was conducted to explore frequency distribution, central tendency, variability (dispersion) and overall distribution of independent variables.

Bivariate logistic regression analysis was conducted to select candidate variables for multivariable analysis. All explanatory variables associated with the outcome variable in bivariate analysis with $p$-value of $<0.25$ were included in logistic models of multivariable analysis using backward stepwise method. Adjusted odd ratio along with 95\% confidence intervals $(\mathrm{CI})$ was used to check the strength of association. Multicollinearity between the independent variable was checked using variance inflation factor. Finally model fitness was done using Hosmer and Lemeshow Statistics, chi-square $\left(x_{x} 2=1.82\right)$ and $p$-value was 0.61 . Variables with $p$ value $<0.05$ were considered as statistically significant. Confidence interval of the outcome variable was (95\%CI; 4.7-11.9).

\section{Ethical considerations}

Ethical approval of the study was obtained from Jimma University institute of health ethical review board. The ethical letter was submitted to Gambella hospital then support letter was obtained from Hospital administration. Written consent was taken after informing the purpose and importance of the study to each participant. To ensure confidentiality of participant's information, codes were used where by the name of the participant and any identifier of participants was not written on the questionnaire. Participants were interviewed alone to keep the privacy. The participants did not pay for the test. Voluntary Participation was clearly stated that they could choose to participate or not; and they could still receive all the services they usually do if they choose not to participate. Test results were given to the clinicians who were working on ANC clinic and medical and psychological management was given for pregnant women who become positive for the test. The clinical specimen collected during the study period was used only for the stated objectives.

\section{Result}

\section{Socio-demographic the respondents}

Two hundred fifty three (respondent rate of 100\%) pregnant women took part in the study. The median age of the study participants was 24 years. One hundred four (41.1\%) pregnant women were between the age group of 21 and 25 years. Two hundred thirty nine (94.5\%) were urban residence. One hundred forty nine (58.9\%) pregnant women were unemployed. One hundred fifty four (60.9\%) pregnant women had above secondary education level $(\geq 9)$ while nineteen $(7.5 \%)$ were who cannot read and write. Sixty three $(30.4 \%)$ pregnant women were Oromo while the rest were other ethnic group.

\section{Sero-prevalence of HBV infection}

The overall sero-prevalence of HBV infection was 20 (7.9\%), 95\% CI; 4.70-11.90). Among these, 7.69\% were between 21- 25 years of age. Twelve (15\%) of respondents with primary education [1-8], and $7(4.55 \%)$ of respondents with secondary and above $(\geq 9)$ education had sero-prevalence of HBV infection. Based on their occupation, $18(12.08 \%)$ of pregnant Women who were unemployed and 2 (1.92\%) of those who were employed had sero- prevalence of HBV infection (Table 1).From total number of respondents, $26.1 \%$ had abortion history and $15(5.9 \%)$ had history of multiple sexual partners experience (Table 2).

From the variables that were included in the multivariable analysis, abortion, occupation and multiple sexual partners were significantly associated with HBsAg serostatus .However, other variables; educational level, splash of body fluids and sharing of earrings, razors and tooth brush which were candidate in bivariate analysis were not significant. Pregnant women who had abortion history had almost four times higher risk of being sero-positive for HBV infection than those pregnant women who had not abortion history (AOR=3.56:95\%CI, 1.24-10.22). Based on multiple sexual partner, pregnant women who had multiple sexual partner were seventeen times more likely to be sero-positive for HBV infection than those pregnant women who had not such partner $(\mathrm{AOR}=17.38: 95 \% \mathrm{CI}$, 4.48-67.49). Regarding their occupation, unemployed pregnant women had eight times higher risk of being sero-positive for HBV infection than those who were employed (AOR= 8.36:95CI, 1.67-41.96) (Table 3).

\section{Discussion}

The result of this study showed that the prevalence of HBsAg among pregnant women attending antenatal care was $7.9 \%$. According to WHO criteria which classifies endemicity of HBV infection; low endemicity areas (less than $2 \%$ sero positive), intermediate endemicity area ( $2 \%$ to $7 \%$ sero positive) and high endemicity area ( $\geq 8 \%$ sero positive), the result showed intermediate endemicity area 
Table 1 Socio-demographic characteristics and sero-prevalence of HBV infection status among pregnant women attending antenatal care at Gambella hospital March $10-$ April 15, 2017. $(N=253)$

\begin{tabular}{|c|c|c|c|c|c|}
\hline \multirow[t]{2}{*}{ Variable } & \multirow[t]{2}{*}{ Category } & \multirow[t]{2}{*}{ Number (\%) } & \multicolumn{2}{|l|}{ HBV } & \multirow{2}{*}{$\begin{array}{l}\text { Crude Odds } \\
\text { Ratio(95\% Cl) }\end{array}$} \\
\hline & & & Positive & Negative & \\
\hline \multirow[t]{3}{*}{ Age } & $16-20$ & $72(28.5 \%)$ & $7(9.72 \%)$ & $66(90.28 \%)$ & $1.55(.47-5.13)$ \\
\hline & $21-25$ & $104(41.1 \%)$ & $8(7.69 \%)$ & 96 (92.31\%) & $1.20(.38-3.82)$ \\
\hline & $\geq 26$ & 77 (30.4\%) & $5(6.49 \%)$ & $72(93.51 \%)$ & 1 \\
\hline \multirow[t]{5}{*}{ Ethnicity } & Oromo & $63(24.9 \%)$ & $4(6.35 \%)$ & $59(93.65 \%)$ & 1 \\
\hline & Agnuwak & $56(22.1 \%)$ & $6(10.7 \%)$ & $50(89.3 \%)$ & $1.77(.47,6.63)$ \\
\hline & Amhara & $43(17 \%)$ & $2(4.65 \%)$ & $41(95.35 \%)$ & $0.72(.13,4.11)$ \\
\hline & Tigre & $31(12.3 \%)$ & $1(3.2 \%)$ & $30(96.8 \%)$ & $0.49(.05,4.59)$ \\
\hline & Others & $60(23.7 \%)$ & $7(11.7 \%)$ & $53(88.3 \%)$ & $1.95(.54,7.03)$ \\
\hline \multirow[t]{3}{*}{ Educational Status } & Cannot read and write & 19 (7.5\%) & $1(5.26 \%)$ & 18 (94.74\%) & $1.18(.14,10.3)$ \\
\hline & $1-8$ & $80(31.6 \%)$ & $12(15 \%)$ & $68(85 \%)$ & $3.71(1.39,9.83)^{*}$ \\
\hline & $\geq 9$ & $154(60.9 \%)$ & $7(4.55 \%)$ & 147 (95.45\%) & 1 \\
\hline \multirow[t]{2}{*}{ Residence } & Urban & $239(94.5)$ & $19(7.95 \%)$ & $220(92.05 \%)$ & 1 \\
\hline & Rural & $14(5.5)$ & $1(7.14 \%)$ & $13(92.86 \%)$ & $0.89(.11,7.18)$ \\
\hline \multirow[t]{2}{*}{ Occupation } & Unemployed & $149(58.9)$ & $18(12.08 \%)$ & $131(87.92 \%)$ & $7.01(1.59,30.89)^{*}$ \\
\hline & Employed & $104(41.1)$ & $2(1.92 \%)$ & 102 (98.08\%) & 1 \\
\hline
\end{tabular}

[18]. The result of this study is in accordance with the hospital based cross-sectional study done at Hawassa University Teaching and Referral Hospital $7.8 \%$ and Seroprevalence of hepatitis B surface antigen among pregnant women attending the Hospital for Women \& Children in Koutiala, Mali 8\% [9, 19]. The result is also almost concordant with the findings found from the study areas of Congo 8.7\% [20] and Addis Ababa 6\% [17]. Among various risk factors abortion, occupation and multiple sexual partner were statistically significant. However, lower and higher prevalence of HBV infection was assessed in similar study populations in different areas of the world. Areas with high magnitude of HBsAg sero-prevalence include $16.5 \%$ in Nigeria and $10.2 \%$ in Cameroon [7, 21]. Some of the areas in which low prevalence of $\mathrm{HBV}$ infection detected were $3.1 \%$ in Rwanda ,4.3\% in Arba Minch and 4.9\% in Dessie [9, 12, $22]$. Even if the study design is similar, Variations in the prevalence of $\mathrm{HBV}$ infection within different parts of the world may be due to differences in the methods used for screening for HBsAg, sample size difference, local government attention for the virus, and cultural and behavioral differences regarding possible risk factors of $\mathrm{HBV}$ infection. With regard to socio-demographic status of study participants, high prevalence 7 (9.72\%) of HBV infection was observed among pregnant women of age 16 to 20 years and low prevalence observed among those with age of 21 and above years, but the difference was not statistically significant. The observed high prevalence of HBV positivity among younger age group could be defined with the high probability of exposure for high risk health behavior but this is contrasted with other studies because high prevalence of HBV infection was found on the study subjects of age greeter than 20 years [11, 22, 23]. Concerning levels of education, it was noted that high prevalence 12 (15\%) of HBV infection was detected among pregnant women who had primary educational [1-8] status and the low prevalence 1 (5.26\%) of HBV infection among those who cannot read and write may be due to their low number in the study. Even if it was not statistically significant ( $p$-value $>0.05)$ which made it different from other study reports conducted in Dessie [10], generally the prevalence of $\mathrm{HBV}$ infection decreased with increasing levels of education which is in line with other studies conducted in different areas $[8,9]$. Although there is no statistical significant difference with residence, pregnant women who were living in urban area had more prevalence19 (7.95\%) of HBV infection than those women living in rural which is in line with other study $[10,11]$. This may be due to urban women could be engaged in risky life style practices. Based on their occupation, pregnant Women who were unemployed had eight times more likely to be sero-positive for HBV infection than employed. This may be due to that employed pregnant women have good awareness about $\mathrm{HBV}$ infection. But this result is in contrast to other results reported from Addis Ababa and Hawassa [8, 9].

According to this study, the prevalence of HBV infection was significantly higher among pregnant women who had history of abortion. The odd of having HBV infection among women with abortion history almost four times higher compared with those who had not abortion history. 
Table 2 Sero-prevalence of HBV infection among pregnant women attending antenatal care at Gambella hospital March 10-April 15,2017. $(N=253)$

\begin{tabular}{|c|c|c|c|c|c|}
\hline \multirow[t]{2}{*}{ Variable } & \multirow[t]{2}{*}{ Category } & \multirow[t]{2}{*}{ Number (\%) } & \multicolumn{2}{|l|}{ HBV } & \multirow{2}{*}{$\begin{array}{l}\text { Crude odds } \\
\text { ratio }(95 \% \text { Cl) }\end{array}$} \\
\hline & & & Positive & Negative & \\
\hline \multirow[t]{2}{*}{ Abortion History } & Yes & $66(26.1 \%)$ & $11(16.67 \%)$ & $55(83.33 \%)$ & $3.96(1.56,10.04)^{*}$ \\
\hline & No & $187(73.9 \%)$ & $9(4.8 \%)$ & $178(95.2 \%)$ & 1 \\
\hline \multirow[t]{2}{*}{ Hospital Admission } & Yes & $61(24.1 \%)$ & $4(6.57 \%)$ & $57(93.43 \%)$ & $0.77(.25,2.40)$ \\
\hline & No & $192(75.9 \%)$ & $16(8.33 \%)$ & $176(91.67 \%)$ & 1 \\
\hline \multirow[t]{2}{*}{ History of blood transfusion } & Yes & $15(5.9 \%)$ & $2(13.33 \%)$ & $13(86.67 \%)$ & $2.24(.46,10.99)$ \\
\hline & No & $238(94.1 \%)$ & $18(7.56 \%)$ & $220(92.44 \%)$ & 1 \\
\hline \multirow[t]{2}{*}{ History of surgical procedure } & Yes & $18(7.1 \%)$ & $1(5.56 \%)$ & $17(94.44 \%)$ & $0.67(.08,5.30)$ \\
\hline & No & $235(92.9 \%)$ & 19 (8.08\%) & 216 (91.92\%) & 1 \\
\hline \multirow[t]{3}{*}{ Place of previous delivery } & No & $99(39.1)$ & $4(4.04 \%)$ & 95 (98.08\%) & $0.56(.12,2.62)$ \\
\hline & Home & $111(43.9)$ & $13(11.71 \%)$ & $98(88.29 \%)$ & $1.77(.48,6.54)$ \\
\hline & Health facility & $43(17.0)$ & $3(6.97 \%)$ & $40(93.03 \%)$ & 1 \\
\hline \multirow[t]{2}{*}{ Multiple sexual partner } & Yes & $15(5.9 \%)$ & $7(46.67 \%)$ & 8 (53.33\%) & $15.14(4.76,48.24)^{*}$ \\
\hline & No & $238(94.1 \%)$ & $13(5.46 \%)$ & 225 (94.54\%) & 1 \\
\hline \multirow[t]{2}{*}{ Tattoo } & Yes & 30 (11.9\%) & $3(10 \%)$ & 27 (90\%) & $1.346(.37,4.89)$ \\
\hline & No & $223(88.1 \%)$ & 17 (7.62\%) & 206 (92.38\%) & 1 \\
\hline \multirow[t]{2}{*}{ Genital mutilation } & Yes & $153(60.5)$ & $10(6.53 \%)$ & $143(93.47 \%)$ & $0.63(.25,1.57)$ \\
\hline & No & $100(39.5)$ & $10(10 \%)$ & $90(90 \%)$ & 1 \\
\hline \multirow[t]{2}{*}{ Human bite } & Yes & 47 (18.6) & $2(4.25 \%)$ & $45(95.75)$ & $0.46(.10,2.07)$ \\
\hline & No & $206(81.4)$ & 18 (8.73\%) & 188 (91.27\%) & 1 \\
\hline \multirow[t]{2}{*}{ Sharp injury } & Yes & $126(49.8 \%)$ & 12 (9.52\%) & 114 (90.48\%) & $1.57(.62,3.97)$ \\
\hline & No & $127(50.25)$ & $8(6.29 \%)$ & 119 (93.71\%) & 1 \\
\hline \multirow[t]{2}{*}{ Needle stick injury } & Yes & $34(13.4 \%)$ & $2(5.88 \%)$ & $32(94.12 \%)$ & $69(.16,3.15)$ \\
\hline & No & $219(86.6 \%)$ & 18 (8.22\%) & 201 (91.78\%) & 1 \\
\hline \multirow[t]{2}{*}{ Sharing of earrings, razors \&tooth brush } & Yes & $11(4.3 \%)$ & $2(18.18 \%)$ & $9(81.82 \%)$ & $2.77(.56,13.78)^{*}$ \\
\hline & No & $242(95.7 \%)$ & $18(7.23 \%)$ & $224(92.68 \%)$ & 1 \\
\hline \multirow[t]{2}{*}{ Splash of body fluids } & Yes & $6(2.4 \%)$ & $2(33.33 \%)$ & $4(66.67 \%)$ & $6.36(1.09,37.12)^{*}$ \\
\hline & No & $247(97.6 \%)$ & $18(7.28 \%)$ & $229(92.72 \%)$ & 1 \\
\hline
\end{tabular}

Table 3 Factors independently associated with HBV infection among pregnant women attending antenatal care at Gambella hospital from March 10-April 15, 2017. $(N=253)$

\begin{tabular}{|c|c|c|c|c|c|}
\hline \multirow[t]{2}{*}{ Variable } & \multirow[t]{2}{*}{ Category } & \multicolumn{2}{|c|}{ HBV sero-status } & \multirow{2}{*}{$\begin{array}{l}\text { Crude odds } \\
\text { ratio(95\% Cl) }\end{array}$} & \multirow{2}{*}{$\begin{array}{l}\text { Adjusted odds ratio } \\
(95 \% \mathrm{Cl})\end{array}$} \\
\hline & & Positive & Negative & & \\
\hline \multirow[t]{2}{*}{ Abortion } & Yes & $11(16.67 \%)$ & $55(83.33 \%)$ & $3.96(1.56-10.04)$ & $3.56(1.24,10.22)^{*}$ \\
\hline & No & $9(4.8 \%)$ & $178(95.2 \%)$ & 1 & 1 \\
\hline \multirow[t]{2}{*}{ Multiple sexual Partner } & Yes & 7 (46.67\%) & $8(53.33 \%)$ & $15.14(4.756-48.22)$ & $17.38(4.48,67.49)^{*}$ \\
\hline & No & $13(5.46 \%)$ & 225 (94.54\%) & 1 & 1 \\
\hline \multirow[t]{2}{*}{ Occupation } & Unemployed & $18(12.08 \%)$ & 131 (87.92\%) & 7.01 (1.59-30.89) & $8.36(1.67,41.96)^{*}$ \\
\hline & Employed & $2(1.92 \%)$ & 102 (98.08\%) & 1 & 1 \\
\hline \multirow[t]{2}{*}{ Splash of body Fluids } & Yes & $2(33.33 \%)$ & $4(66.67 \%)$ & $6.36(1.09-37.12)$ & $6.79(1.57,80.25)^{*}$ \\
\hline & No & $18(7.28 \%)$ & 229 (92.72\%) & 1 & 1 \\
\hline
\end{tabular}


It is known that, multiple sexual practices may cause unplanned pregnancy which may result abortion and increase the risk of $\mathrm{HBV}$ infection if such partners are infected. Accordingly, contaminated instruments used during abortion procedure might increase the probability of acquiring HBV infection. This is similar with a study result reported from Nigeria, Arba Minch, Debre-Tabor and Addis Ababa [7, 12, 17, 24]. When previous place of delivery considered, pregnant women who delivered at home had $13(11.71 \%)$ sero-prevalence of HBV infection while those who delivered at hospital had 3 (6.97\%) seroprevalence. The possible reason may be unsafe delivery practice at home. This is in agreement with a study report from other area of Ethiopia [9]. Except abortion, medical related risk factors like blood transfusion, surgical procedures, place of previous birth and hospital admission were not associated with seropositivity for $\mathrm{HBsAg}$ in this study ( $p$-value $>0.05$ ). This may be due to the use of standard procedures and disinfected instruments by health professionals. The result is in agreement with previous study conducted at Hawassa, Dessie and Congo $[9,10,20]$. But hospital admission and surgical procedures were statistically significant with high HBsAg sero-prevalence on a studies conducted in Shashemene [25] and Addis Ababa [17] respectively.

Concerning to behavioral and cultural risk factors, pregnant women who had multiple sexual partner had about 17 times higher risk of being sero-positive for HBV infection than pregnant women who had not history of multiple sexual partner. The significant association of having multiple sexual partner with HBV infection was also reported by other investigators $[10,12]$. In this study risk factors like tattooing, piercing, genital mutilation and human bites were not associated with seropositivity of HBsAg ( $p$-value $>0.05$ ). This is similar with a previous study conducted in Addis Ababa and Hawassa [8, 9],on the other hand, another studies conducted in Debretabor and Nigeria (Osogbo) showed that, in contrast to this study body tattooing was associated with prevalence of HBV infection [7, 13, 24]. This variation may be due to cultural practice differences and different materials used during tattooing.

According to this study, only Sharing of earrings, razors and tooth brush and splash of body fluids were significant during bivariate analysis but in the multivariate analysis none of these accidental risk factors assed were associated with prevalence of HBV infection. Among these risk factors history of sharp injury was statistically significant during a study conducted in Debretabor [24].

Unless preventive measures through vaccination are taken to tackle the risk of transmission, the unborn babies are at a higher risk of contracting HBV infection. The infection was significantly higher among pregnant mothers who had aborted previously and had history of sex with multiple sexual partners. In this study, due to lack of laboratory setup, markers of HBV like $\mathrm{HBeAg}$, HBV-DNA were not detected. Therefore, the major limitation of the study was the new infection of HBV in blood and its active period status not included.

\section{Conclusion}

This study showed that sero-prevalence of HBV infection among pregnant women in Gambella hospital intermediate endemicity. Abortion, occupation and multiple sexual partners significantly associated with HBV infection among pregnant women. Therefore, to halt spread of the virus, health education on modes of transmission like having multiple sexual partners and abortion should be considered. In addition to this, routine screening and immunization of all pregnant women and their infants should be continued in the antenatal and postnatal programs in health facilities.

\section{Abbreviations \\ ALT: Alanine Amino Transferase; ANC: Anti Natal Care; CHB: Chronic Hepatitis B; DNA: Deoxyribo Nucleic Acid; HBcAg: Hepatitis Core Antigen; \\ HBeAg: Hepatitis e antigen; HBsAg: Hepatitis B Surface Antigen; HBV: Hepatitis B Virus; HCC: Hepatocellular Carcinoma; HCV: Hepatitis C Virus; HIV: Human Immune Virus; IU/L: International Unit per Litter; SPSS: Statistical Package for Social Sciences; WHO: World Health Organization}

\section{Acknowledgements}

We would like to acknowledge Jimma University for giving us this opportunity to conduct the study. Additionally, we would like to thank study participants, health care personnel who were helped us in the data collection.

\section{Authors' contributions}

AT: Involved in generating the concept of this research paper, proposal writing, designing, analysis, write-up, preparation of scientific paper, and manuscript preparation; MA: Involved in generating the concept of this research paper, proposal writing, designing, analysis, write-up, and approval of final manuscript; $\mathrm{DH}$ : supported in proposal writing, designing, analysis, and approval of final manuscript; CF: supported in proposal writing, designing, analysis, and approval of final manuscript; GK: Involved in generating the concept of this research paper, proposal writing, designing, analysis, write-up, preparation of scientific paper, and manuscript preparation. All authors read and approved the final manuscript.

\section{Funding}

Not applicable.

\section{Availability of data and materials \\ The datasets analyzed during the current study are available from the corresponding author on reasonable request.}

\section{Ethics approval and consent to participate}

Ethical approval of the study was obtained from Jimma University institute of health ethical review board. The ethical letter was submitted to Gambella hospital then support letter was obtained from Hospital administration. Written consent was taken after informing the purpose and importance of the study to each participant. To ensure confidentiality of participant's information, codes were used where by the name of the participant and any identifier of participants was not written on the questionnaire. Participants were interviewed alone to keep the privacy. The participants did not pay for the test. Voluntary Participation was clearly stated that they could choose to participate or not; and they could still receive all the services they usually do if they choose not to participate. Test results were given to the clinicians who were working on ANC clinic and medical and psychological management was given for pregnant women who become positive for the test. The clinical 
specimen collected during the study period was used only for the stated objectives.

\section{Consent for publication}

Not applicable.

\section{Competing interests}

The authors declare that they have no competing interests.

\section{Author details}

'Gambella Reginal Health Bureau, Gambella, Ethiopia. ${ }^{2}$ Jimma University institute of health science, Jimma, Ethiopia. ${ }^{3}$ Arba Minch University College of health science, Arba Minch, Ethiopia.

Received: 12 May 2018 Accepted: 26 June 2019

Published online: 10 July 2019

\section{References}

1. WHO. Guidelines for the prevention, care and treatment of persons with chronic hepatitis b infection. Geneva; 2015. http://www.who.int/hiv/topics/ hepatitis/en/.

2. WHO, UNICEF, World Bank. State of the world's vaccines and immunization, 3rd ed. Geneva: World Health Organization; 2009.

3. Bosse T. Infectious Disease Epidemiology Report; 2015.

4. Mauss, Berg, Rockstroh, Sarrazin, Wedemeyer. Hepatology a clinica textbook. 7th ed. Koblenz: Druckerei Heinrich GmbH; 2016.

5. Ikobah J, et al. The prevalence of hepatitis B virus infection in Nigerian children prior to vaccine introduction into the National Programme on Immunization schedule. Pan Afr Med J. 2016;23:128. https://doi.org/10.116 04/pamj.2016.23.128.8756.

6. World Health Organization. Hepatitis B Fact sheet No 204. []. Available from: URL: http://www.who.int/mediacentre/factsheets/fs204/en/. Accessed 7th Mar 2016.

7. Kolawole OM, Wahab AA, Adekanle DA, Sibanda T, Okoh A. Sero-prevalence of hepatitis B surface antigenemia and its effects on hematological parameters in pregnant women in Osogbo, Nigeria. Virol J. 2012;9:317.

8. Tegegne D, Desta K, Tegbaru B, Tilahun T. Seroprevalence and transmission of Hepatitis $B$ virus among delivering women and their new born in selected health facilities, Addis Ababa,Ethiopia: a cross sectional study. BMC Res Notes. 2014;7:239.

9. Metaferia Y, Dessie W, Ali I, Amsalu A. Seroprevalence and associated risk factors of hepatitis $B$ virus among pregnant women in southern Ethiopia: a hospital-based cross-sectional study. Epidemiol Health. 2016;38:2016027.

10. Seid M, Gelaw B, Assefa A. Sero-prevalence of HBV and HCV infections among pregnant women attending antenatal Care Clinic at Dessie Referral Hospital, Ethiopia. Adv Life Sci Health. 2014;1(2):109-20.

11. Chernet A, Yesuf A, Alagaw A. BMC Res Notes. 2017;10:418. https://doi.org/1 0.1186/s13104-017-2702-x.

12. Yohanes T, Zerdo Z, Chufamo N. Seroprevalence and predictors of Hepatitis $B$ virus infection among pregnant women attending routine antenatal Care in Arba Minch Hospital, South Ethiopia. Hepat Res Treat. 2016;2016(2):1-7.

13. Zenebe, et al. Sero-prevalence and risk factors of hepatitis B virus and human immunodeficiency virus infection among pregnant women in Bahir Dar city, Northwest Ethiopia: a cross sectional study. BMC Infect Dis. 2014:14:118.

14. Tse KY, Ho LF, Lao T. The impact of maternal HBsAg carrier status on pregnancy outcomes:case-control study. J Hepatol. 2005:43 Epub 775.

15. Zhang S, Zhou Y. The analysis and application of an HBV model. Appl Math Model. 2012:36:1302-12

16. Afzali H, Heravi MM, Moravveji SA, Poorrahnama M. Prevalence of Hepatitis B surface antigen in pregnant women in Beheshti Hospital of Kashan, Isfahan. Iran Red Crescent Med J. 2015;17(7):e20598.

17. Desalegn Z, Wassie L, Beyene HB, Mihret A, Ebstie YA. Hepatitis B and human immunodeficiency virus co infection among pregnant women in resource limited high endemicsetting, Addis Ababa, Ethiopia: implications for prevention and control measures. Eur J Med Res. 2016;21:16. https://doi. org/10.1186/s40001-016-0211-3

18. WHO. Introduction of hepatitis B vaccine into childhood immunization services. 2001

19. Maclean B, Hess RF, Bonvillain E, Kamate J, Dao D, Cosimano A et al. Seroprevalence of hepatitis $B$ surface antigen among pregnant women attending the Hospital for Women \& children in Koutiala, Mali. SAMJ. 2012:102(1):47-9.

20. Angounda BM, Dzia AB, Boumba LMA, Clotaire I, Ahombo G, et al. Prevalence of serologic markers and risk factors for Hepatitis $B$ virus among pregnant women in Brazzaville, Congo. Int J Sci Res. 2016;5(1):1907-12.

21. Noubiap JJN, Nansseu JRN, Ndoula ST, Bigna JJR, Jingi AM, Fokom-Domgue J. Prevalence, infectivity and correlates of hepatitis B virus infection among pregnant women in a rural district of the far north region of Cameroon. BMC Public Health. 2015;15:454

22. Nyamusi MM, Marete OT, Waweru WR. Seroprevalence of hepatitis B among pregnant women in Kigali, Rwanda. Int J Community Med Public Health. 2016;3(11):3096-101.

23. Alegbeleye JO, Nyengidiki TK, Ikimalo Jl. Maternal and neonatal seroprevalence of hepatitis B surface antigen in a hospital based population in south-south, Nigeria. Int J Med Med Sci. 2013:5(5):241-6.

24. Walle F, Asrat D, Alem A, Tadesse E, Desta K. Prevalence of hepatitis b surface antigen among pregnant women attending antenatal care service at Debre-Tabor hospital, Northwest Ethiopia. Ethiop J Health Sci. 2008;17(1):13-21.

25. Medhin ANZS. Prevalence of Hepatitis B surface antigen (HBsAg) among visitors of Shashemene general hospital voluntary counseling and testing center. BMC Res Notes. 2011:4:35.

\section{Publisher's Note}

Springer Nature remains neutral with regard to jurisdictional claims in published maps and institutional affiliations.
Ready to submit your research? Choose BMC and benefit from:

- fast, convenient online submission

- thorough peer review by experienced researchers in your field

- rapid publication on acceptance

- support for research data, including large and complex data types

- gold Open Access which fosters wider collaboration and increased citations

- maximum visibility for your research: over $100 \mathrm{M}$ website views per year

At $\mathrm{BMC}$, research is always in progress.

Learn more biomedcentral.com/submissions 